\title{
Chapter 7 \\ Geospatial Analysis of Persistent Organic Pollutant Deposits in the Arctic Ecosystems and Environment
}

\author{
Vladimir A. Kudrjashov
}

\begin{abstract}
The study was conducted to determine the distribution of accumulation of persistent organic pollutants (POPs) in the ecosystem components and environment in the Arctic regions of Russia. A GIS software was used to obtain data from regions and locations for which POP concentrations exceeded threshold values or remained within the normal range. The geospatial analysis was carried out for sea water, sea-bed sediments, and marine and terrestrial ecosystem components. The accumulation coefficients of POPs in the ecosystem components and environment were calculated. The obtained data analysis gave an opportunity to demonstrate the accumulation of POPs in the ecosystems. By data modeling it was determined that there is an exponential character of the POP accumulation in the components of Arctic ecosystems and environment.
\end{abstract}

\subsection{Introduction}

In the last decades, there has been a global growth in industrial activity, mining and agriculture intensification. Various pollutants are produced as a result of these processes. Among these pollutants are the persistent organic pollutants (POPs), such as DDT (dichlorodiphenyltrichloroethane), PCB (polychlorinated biphenyl) and $\mathrm{HCH}$ (hexachlorocyclohexanes), that remain active over a long period of time and also accumulate in the Arctic food chain in ecosystems and environment (Arctic Pollution 1998; AMAP 2004). POPs can have negative influence on ecosystems and environment, for example by disturbing the physiological functions of biota, polluting food chains, and by environmental contamination (Arctic Pollution 1998; Crane 2000;

\footnotetext{
V.A. Kudrjashov $(\bowtie)$

Russian State Hydrometeorological University, Saint-Petersburg, Russia

e-mail: vakudrjashov@ rambler.ru 
AMAP 2004). POPs are a large group of toxic organic substances. Chlorine ions are included frequently in the chemical composition of POPs as a one of their components. These compounds are named chlorinated hydrocarbons. Some of the POPs are direct or collateral products of industrial production, whereas other POPs have been produced or are produced as pesticides.

Transboundary transportation of trace amounts of POPs causes them to migrate into the Arctic from other parts of the Earth. Biomagnification effect is created due to the POP accumulation in the food chains of Arctic ecosystems (Arctic Pollution 1998; Crane 2000). By entering into polar biota, POPs can dissolve and accumulate in their fat tissues and then through the ecosystem chain by transfer from the lower parts of the food chains to higher ones with increasing POPs concentrations. Artificial organic chemical substances are very persistent to decompose in the arctic natural environment that is characterized by limited sunlight and lower temperature range. A forecast made with a help of mathematical model for a well-known pesticide, DDT decay indicated a decrease in pesticide mass from the initial concentration in air (10\%), seawater (1-2\%) and soil (30\%) in ten years' time (Arctic Pollution 1998). POPs accumulated in the arctic biota are ingested with the traditional food of the indigenous peoples and can cause various physiological disturbances and diseases (Arctic Pollution 1998; Crane 2000; AMAP 2004).

\subsection{Material and Methods}

Geospatial analysis and modelling of contaminant concentrations of large regions provides an opportunity to (i) estimate the amount and location of pollutants, (ii) establish their dynamics and to (iii) predict POPs behavior in ecosystems and environment. This study focused on two toxic anthropogenic chlorinated hydrocarbons with heavy molecular weights: dichlorodiphenyltrichloroethane (DDT) and polychlorinated biphenyl (PCB). The geospatial analysis was made in the ArcGIS software environment.

The aims of the study included (i) quantitative evaluation of the two POP spatial distribution, (ii) comparison of their concentrations in the examined areas with threshold concentrations, (iii) calculation of two POP accumulation coefficients in the natural environment including sea water and sediments as well as in the components of arctic marine and terrestrial ecosystems. The geospatial analysis was carried out by using theme series of raster picture maps from the Arctic environmental atlas (Crane 2000), which were added as temporal grid-layers to the respective ArcGIS project. The threshold values indicating DDT and PCB values above the normal concentration range for environmental components and biota were obtained from tables in the Supplement B: Normal and threshold values of pollutant concentrations (Crane 2000).

Polluted habitats and regions were digitized manually into ArcGIS. Digitized polygon areas were calculated. The areas having equal pollutant concentrations were merged and calculated. 
The conceptual model was created for estimation of the POP spatial impact in the Arctic ecosystems and environment. The model included an interactive histogram calculated on the basis of the merged polygon areas with the various POP concentrations. In the histogram, the abscissa axis shows the POP concentrations and the ordinate axis shows the merged polygon areas. The interactive histogram provided an opportunity to visualize and analyse the geospatial distribution of areas with various POP concentrations. A vertical red line was overlaid on the histogram. The line represents the threshold value of the POPs for various biota and environment components (Crane 2000). By using the red line as an indication, one can obtain the regions and locations for which the POP concentrations exceeded the threshold values or remained within the normal values.

The realization of the conceptual model for surface sea-bed sediment DDT pollution is presented in Fig. 7.1. Vertical red line on the interactive histogram shows the threshold value equal to $46 \mathrm{ng} / \mathrm{g}$ for the sediment (Crane 2000). All DDT concentration classes visualized on the interactive histogram did not exceed the threshold value.

Fourteen thematic vector data map layers of ArcGIS project were analysed by the conceptual model approach. The thematic data map layers contained areas polluted with DDT and PCB in various locations and concentrations. In the ArcGIS project, the following thematic data map layers were included for DDT: sea water, surface sea-bed sediments, seals (fat), beluga whales (fat). In the ArcGIS project, the following thematic data map layers were included for PCB: surface sea-bed sediments, seals (fat), beluga whales (fat), seagulls (liver), polar bears (fat), caribous

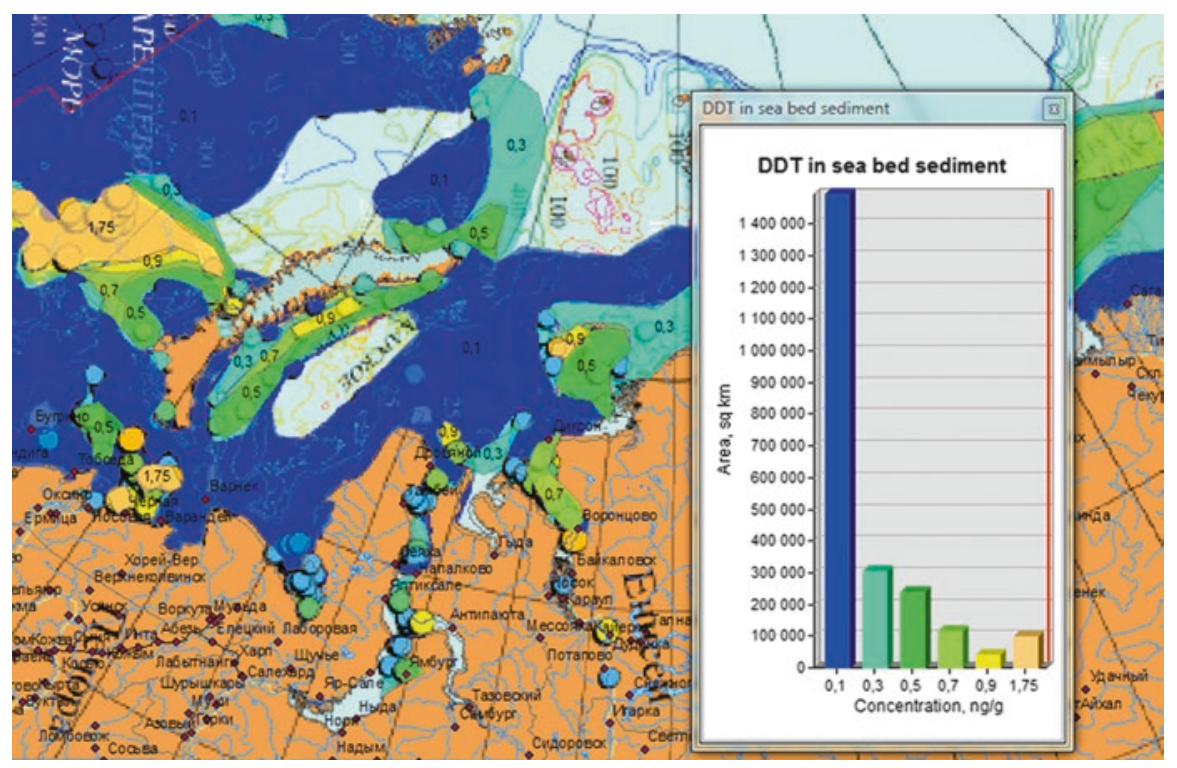

Fig. 7.1 The geospatial distribution of the DDT concentration in sea-bed sediments, based on the conceptual model 
(liver), peoples (blood), peoples (breast milk fat). The analysis of DDT focused on two time periods of 10-15 years (1970-1985 and 1986-1996), providing an opportunity to compare the concentrations between the two time periods and to determine the pollutant concentration dynamics. The data for DDT and PCB concentrations were obtained from a series of raster picture thematic maps of the Arctic environmental atlas (Crane 2000) during its digitalization.

\subsection{Results and Discussion}

The results of the geospatial analysis revealed that a considerable part of the investigated areas had POP pollution. Nevertheless, only a small part of these areas had DDT or PCB concentrations that exceed the threshold values. Exceeding concentrations were identified in six of the investigated themes. These themes for DDT were sea water (two investigation periods) and beluga whales (fat). For PCB they were: seals (fat), beluga whales (fat) and polar bears (fat). Pollutant locations and areas of the given themes were determined and described. Comparison of the data obtained from the two investigation periods did not allow determination whether the POP accumulation was increasing or decreasing.

Subsequent advanced geospatial analysis included the calculation of accumulation coefficients for every POP in the biota components and environment. The accumulation coefficients were calculated with the formula: $K_{a}=C_{f} / C_{p}$, where $K_{a}$ - POP accumulation coefficient, $C_{f}$ - concentration of POPs in the following ecosystem level, $C_{p}$ - concentration of POPs at the previous ecosystem level. The formula includes pollutant concentrations which are attributive values of geospatial polygonal GIS objects. They were calculated as an average POP concentration for every theme of investigation.

These pollutant concentrations, obtained from raster picture thematic maps of the Arctic environmental atlas (Crane 2000) were included into attribute tables of polygonal GIG objects. They were calculated as an average POP concentration for every theme of investigation or ecosystem components. The average POP concentration was calculated with the formula: $C_{e c}=\sum_{i=1}^{n} C_{i} / n$, where $C_{e c}-$ average concentration of POPs in the ecosystem component, $C_{i}$ - concentration of POPs in the merged thematic map polygon, $n-$ the number of merged thematic map polygons. For example in Fig. 7.1 one can see the set of DDT concentrations in the surface sea-bed sediments presented on abscissa axes. The average concentration DDT in the ecosystem component i.e. in the surface sea-bed sediment is $C_{e c}=0.71 \mathrm{ng} / \mathrm{g}$. The POP concentration values for geospatial analysis presented in Figs. 7.2, 7.3, 7.4, 7.5, and 7.6 were calculated by means of the described method and presented formula. The values of $C_{e c}$ were shown near the data symbols or above diagram bars in the Figs. 7.4, 7.5, and 7.6.

Results of the $K_{a}$ calculations are presented in Figs. 7.2 and 7.3. 


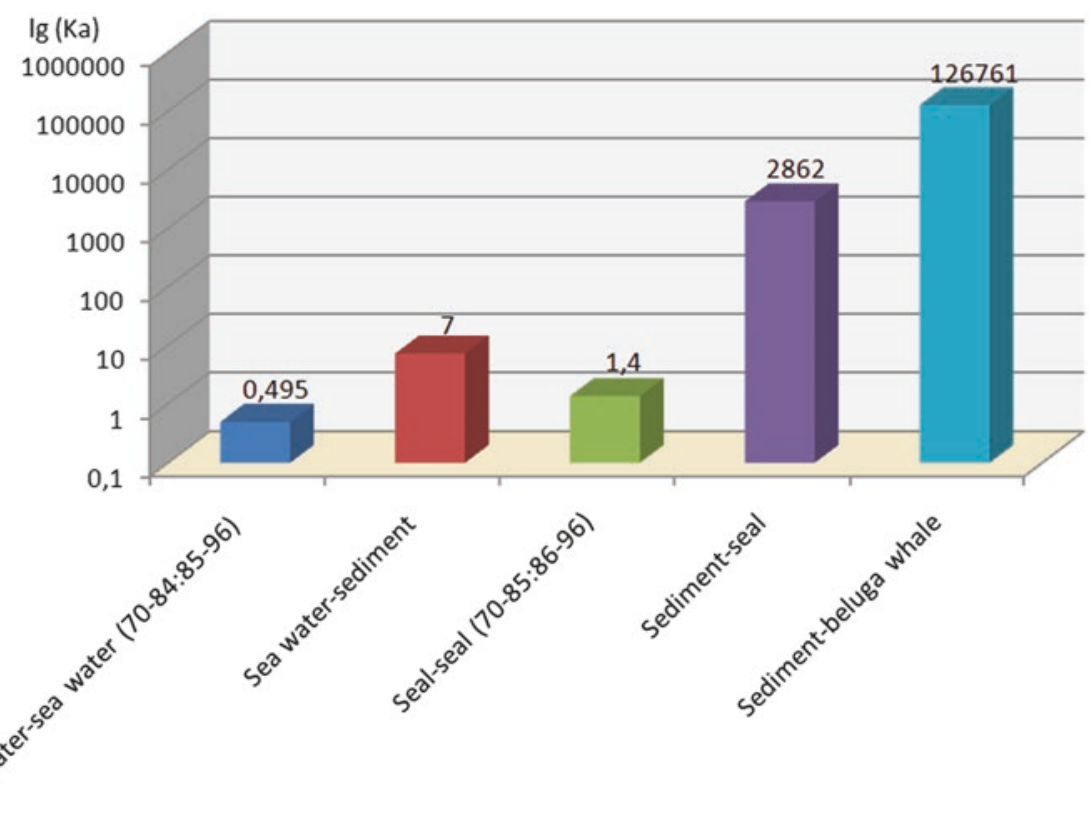

Fig. 7.2 Accumulation coefficients $\left(K_{a}\right)$ for DDT in the marine ecosystem components. Numbers above bars represent $K_{a}$ values

Accumulation coefficient values for DDT between the abiotic and biotic ecosystem components and between the two studied time intervals are presented in Fig. 7.2. Data analysis shows a well-detected trend of accumulation coefficient increase for transition from one abiotic component - sea water- to another component - sea bed sediment- and also from abiotic ecosystem components to biotic ones. The two time intervals on the DDT accumulation coefficient was not obtained in the sea water case, but $K_{a}$ was obtained for the seal one.

The PCB accumulation coefficient values for marine and terrestrial ecosystem components are represented in Fig. 7.3. Absence of data for the PCB accumulation in the sea water is caused by the following factors: (i) PCB is accumulated in the water top layer on sea water - atmospheric boundary. The layer thickness varies from some microns to $1 \mathrm{~mm}$. PCB concentration many times increases in the layer. (ii) In the sea water mass, PCB is absorbed by suspension and settles on the sea bed (Crane 2000). High accumulation coefficient values in the marine ecosystem components represented in Fig. 7.3 are observed in the transition from abiotic component to biotic ones and also in the biotic component itself. In the terrestrial ecosystem components, a considerable accumulation coefficient value was obtained when comparing the PCB concentration in the caribou liver tissue and in the breast milk fat.

More generalized analysis was carried out to obtain the quantitative characteristics and calculate equations connecting POP accumulations and Arctic ecosystem 


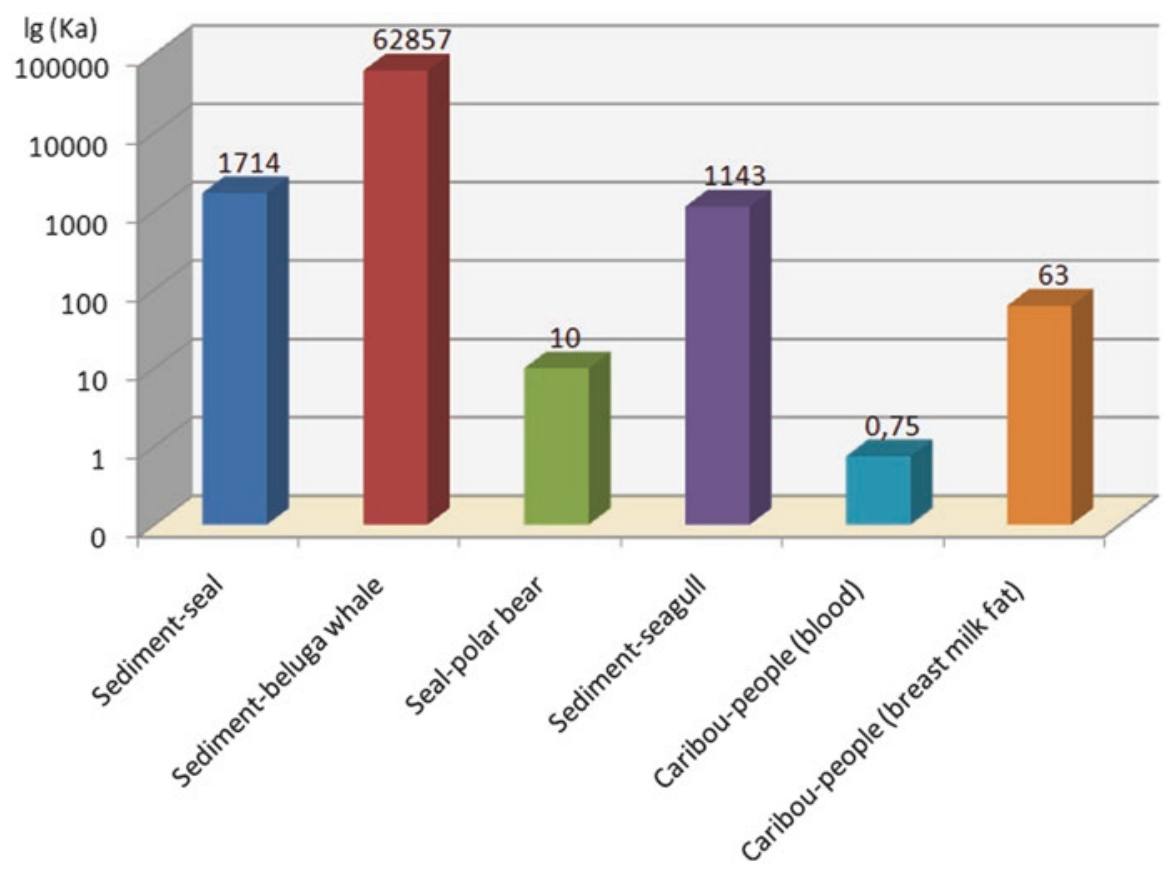

Fig. 7.3 Accumulation coefficients $\left(K_{a}\right)$ for PCB in the marine and terrestrial ecosystem components. Numbers above bars represent $K_{a}$ values

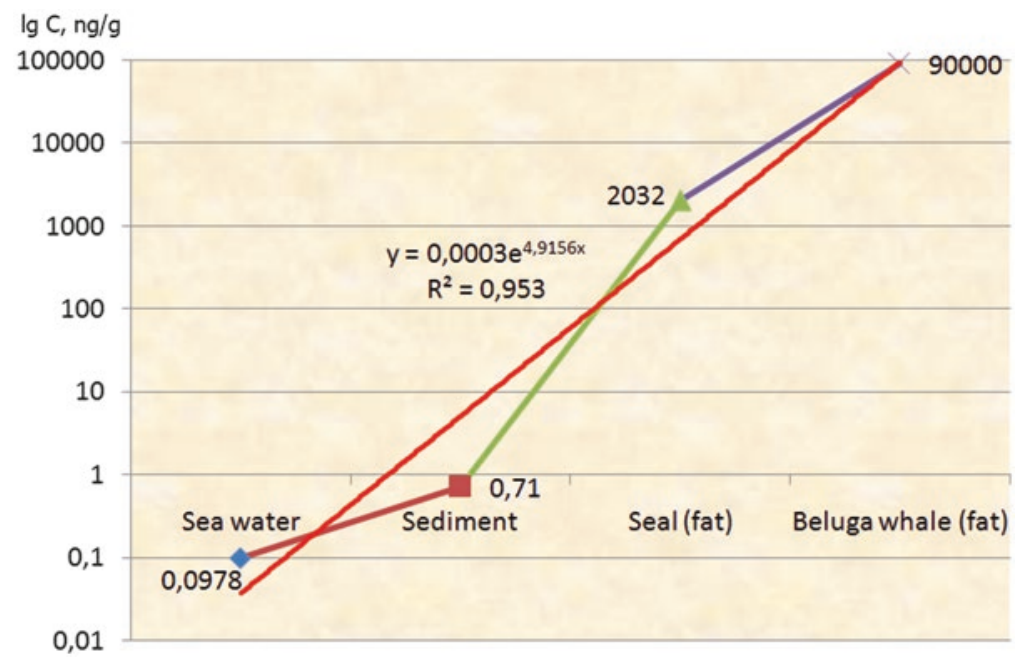

Fig. 7.4 The DDT concentrations in the marine ecosystem components. Numbers near the symbols represent the DDT concentrations (ng/g) 

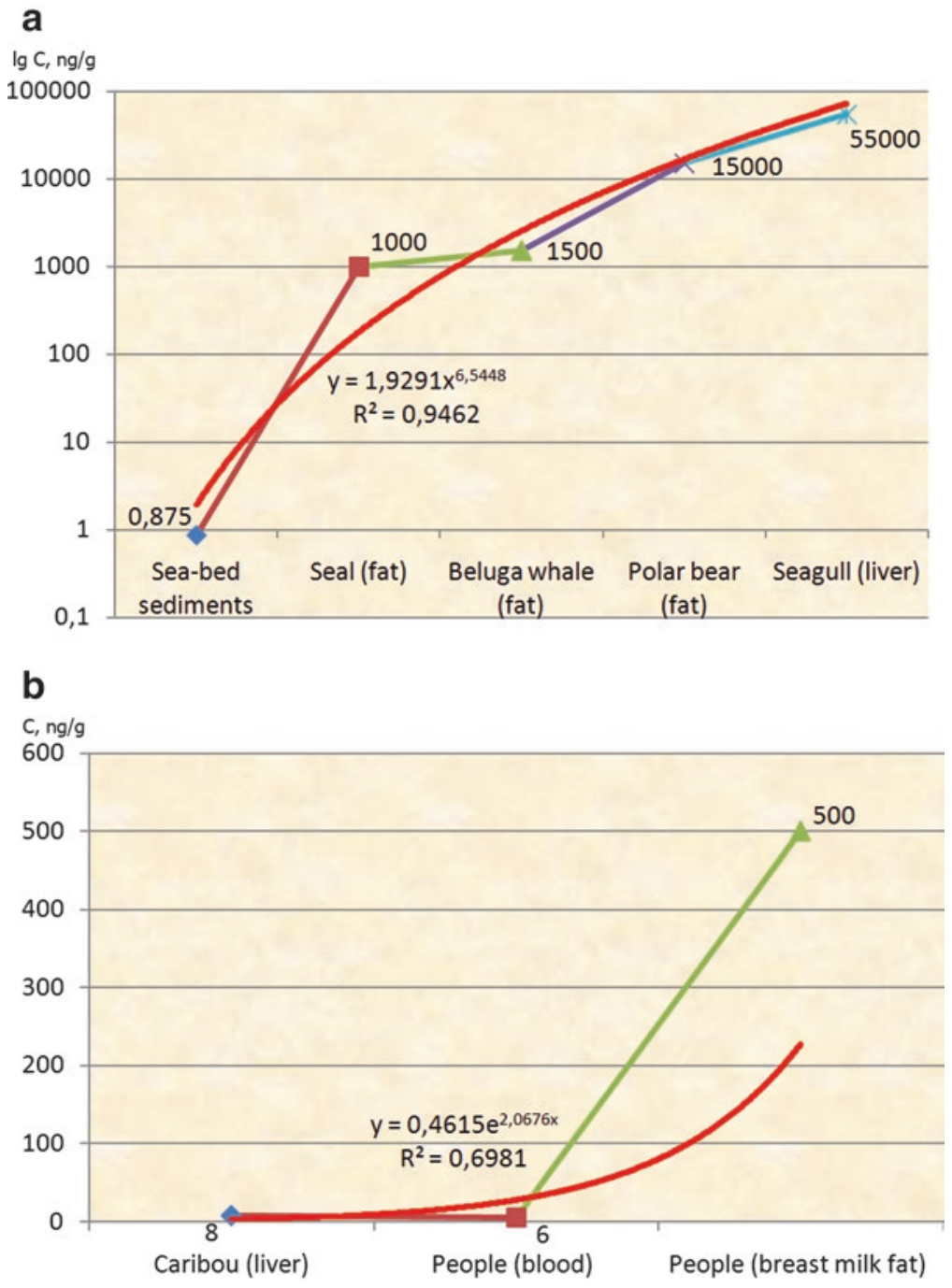

Fig. 7.5 PCB concentrations (a) in the marine ecosystem components, (b) in the terrestrial ecosystem components. Numbers near the symbols present the PCB concentrations (ng/g)

components. The relationships between POP concentrations and various ecosystem components and related equations are presented in Figs. 7.4 and 7.5.

The data analysis presented in Fig. 7.4 shows that DDT concentrations are sharply increasing in the ecosystem components. The increase in concentration is characterized by exponential dependence and is expressed in the equation presented in the figure.

Analysis of the PCB accumulation in the marine and terrestrial ecosystems components is presented in Fig. 7.5. PCB concentration shows an exponential increase 
a

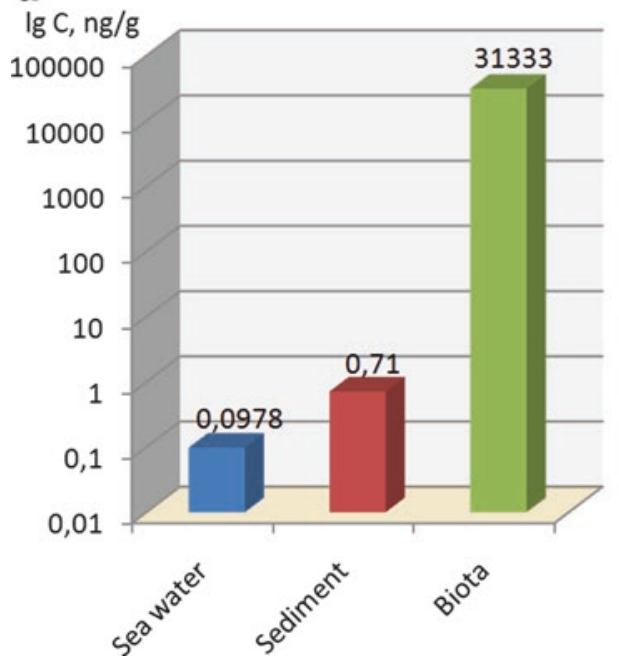

b

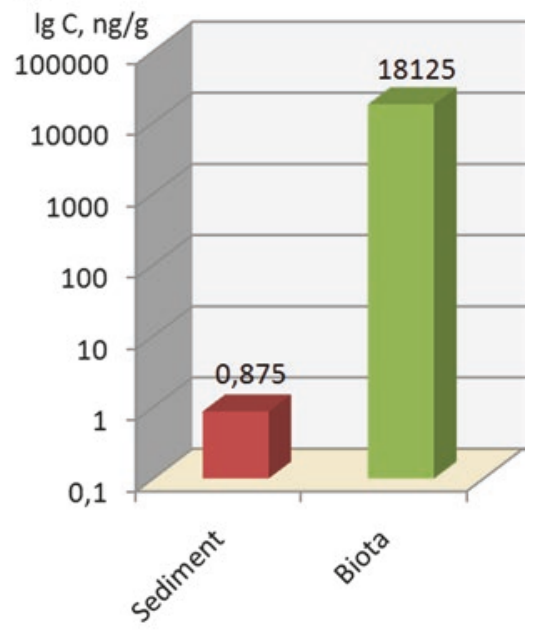

Fig. 7.6 POP magnification effect in the Arctic ecosystem components (a) for DDT, (b) for PCB. Numbers above the bars represent the POP concentrations (ng/g)

in the ecosystem components for both of the studied ecosystem. Related exponential equations are presented for both ecosystem components.

The magnification for DDT and PCB in the biota and environment is presented in Fig. 7.6. The average pollutant concentration in the sea water, sea-bed sediment and biota were used for the diagrams. The analysis of the diagram indicated that a considerable increase in the POP accumulation upwards in the hierarchical level of investigated ecosystems took place.

\subsection{Conclusions}

A geospatial analysis of the concentrations and distribution of two POPs, DDT and PCB, in the Russian Arctic regions showed, that these pollutants are present in most parts of the Russian Arctic, but that their observed concentrations do not exceed the threshold values in most parts of the investigated territories. Furthermore, it was determined that POP accumulation showed an exponential increase in the studied Arctic ecosystem components and environment, and that the magnification effect of the POP accumulation took place in the Arctic ecosystem components and environment. 


\section{References}

AMAP (2004) Assessment 2002: persistent organic pollutants in the Arctic. Oslo, AMAP

Arctic Pollution (1998) Report about Arctic Environment State. AMAP. Hydrometeoisdat, Saint-Petersburg

Crane K (2000) Arctic environmental atlas. VNII Okeangeologia, WWF-USA and WWF Russian Programme Office

Open Access This chapter is licensed under the terms of the Creative Commons Attribution 4.0 International License (http://creativecommons.org/licenses/by/4.0/), which permits use, sharing, adaptation, distribution and reproduction in any medium or format, as long as you give appropriate credit to the original author(s) and the source, provide a link to the Creative Commons license and indicate if changes were made.

The images or other third party material in this chapter are included in the chapter's Creative Commons license, unless indicated otherwise in a credit line to the material. If material is not included in the chapter's Creative Commons license and your intended use is not permitted by statutory regulation or exceeds the permitted use, you will need to obtain permission directly from the copyright holder.

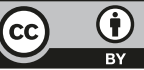

